\title{
INSILICO DESIGNING OF POTENT DRUG TARGETED TO SJOGREN'S SYNDROME ANTIGEN LA (SSB) OF SYSTEMATIC LUPUS ERYTHEMATOSUS
}

\author{
Ashish Kumar Mishra ${ }^{1}$, ManasRanjan Barik ${ }^{2}$ \\ ${ }^{I}$ Research Student, Bengal College of Engineering and Technology and DNA Labs India, India \\ ${ }^{2}$ Research Supervisor, DNA Labs India, Andhra Pradesh, India
}

\begin{abstract}
An autoimmune disease has always been an eye candy for researchers. There have been plenty of researches done all over the world on the various autoimmune diseases. Systemic Lupus Erythematosus (SLE) is one such kind disease which lacks a complete cure. Various databases concluded on targeting the sjogren syndrome antigen B (SSB) gene. The role of SSB gene in SLE is very significant. The gene not only send wrong signal to the Apoptotic cells, but also produces auto antigens which causes the autoimmune disorder, causing the disease. The steps of this research will be including the sequence analysis followed by Phylogenetic analysis on the protein sequence. The structural analysis and drug molecule selection is also obtained. The selected drug molecules are tested for LIPINSKI rule of 5 and ADMET test. Those drugs which qualify the test are minimized along with the protein. Docking tools like HEX, Discovery Studio, and GOLD are used to analyse the compound that binds best and targets the problematic La protein. After analysis, sterol proves to be the best compound.
\end{abstract}

Keywords: Autoimmune, Systematic Lupus Erythematosus, Sjogren Syndrome Antigen B (SSB) gene

\section{INTRODUCTION}

Systemic Lupus Erythematosus is an auto immune disorder that causes inflammation and chronic disorder. It may affect the skin, joints, kidneys, and other organs[1-3]. An auto immune disorder is a condition that occurs when the immune system mistakenly attacks and destroys healthy body tissue. There are more than 80 different types of auto immune disorders.

SLE (lupus) is an auto immune disease. This means there is a problem with the body's normal immune system response. Normally, the immune system helps protect the body from harmful substances. But in patients with an auto immune disease, the immune system can't tell the difference between harmful substances and healthy ones. The result is an over active immune response that attacks otherwise healthy cells and tissue. This leads to chronic(long-term) inflammation. The underlying cause of auto immune diseases is not fully known. Some researchers believe that auto immune diseases occur only after an infection occurs with an organism that apparently looks like certain proteins in the body. The proteins are later mistaken for the organism and wrongly targeted for attack by the body's immune system. SLE may be mild or severe enough to cause death. SLE affects nine times as many women as men. It may occur at any age, but appears most often in people between the ages of 10 and 50 years. African Americans and Asians are affected more often than people from other races. Another important condition that is seen is inflammation of various parts of the heart which may occur as pericard it is, end ocard it is, or my ocarditis[4]. Chest pain and arrhythmias may result from these conditions.

\subsection{Responsible Genetic Cause}

After going through a lot of Journals and research papers on Lupus Erythematosus, it is found out that there are many genes and proteins playing an important role in this disease [5-6]. The huge number of genes and proteins makes the process of selecting the target gene quite complex. In order to select the best target protein for the disease, help was taken by the various research papers and journals along with online information.

Here, it is found out that there are many genes and proteins playing an active role in the disease Systemic Lupus Erythematosus [7-8]. However, amongst all the genes, a particular order was found on which their priority was determined. Determining and analyzing the various factors, we found out that Sjogren Syndrome AntigenB (SSB) is one of the major protein gene involved in the cause of this disease. This particular gene plays a very important role in the disease.

\subsection{Sjogren Syndrome AntigenB}

Sjogren Syndrome AntigenB (SSB) is popularly known as LaProtein. This protein has high and intense involvement in the SLE. Various researches and journals have also thrown light upon this particular protein and have showed how deeply the disease SLE is related to this protein [9-12]. There are many ways in which Laprotein is involved in RNA metabolism, including binding and protecting 3primeUUU $(\mathrm{OH})$ elements of newly RNA polymer as eIII; transcribed RNA, processing at 5-prime and 3-prime ends of pre-t RNA precursors, functioning as an RNA chaper one, and combing viral RNAs associated with Hepatitis Cvirus. 


\section{METHODOLOGY}

It is determined a suitable drug for the target protein SSB, involved in the disease Sytemic Lupus Erythematosus.

\subsection{Drug Molecule Selection}

There were various factors that were to be considered while choosing the compounds. In those circumstances, the best option was to go for the natural compounds, because natural compounds have very high absorbing ability in the body and the toxic effect is also very low [5]. This does not mean that any natural compound is to be taken. The ones which are known to have a good and efficient effect on the disease LUPUSERYTHEMATOSUS is to be considered. Various researches and analysis of various compounds gave us certain results upon which our further analysis was dependent. Once the protein molecule was ready with all the necessary features, it is to be ready for the selection of lig and molecule. After the selection of the natural compounds, there sponse towards the various parameters was to be taken into account. This was because the molecule which is taken a drug, and thus, have to function properly in the human body. Any difference or malfunction can crop another problem in the body [6].

ADMET is another important test that the drug molecules will have to undergo. All the selected drug molecules which pass the LIPINSKIRULEOF5 have to undergo the ADMET results where the Absorption, Distribution, Metabolism, Excretion, and Toxicity of the drugs are analyzed [7-10]. The tool used is DISCOVERY STUDIO. The molecules which obey both these results are then taken in for further analysis in the course of development of the suitable drug.

\subsection{ADMET of Sterol}

Here is the point plot diagrammatic result of the drug STEROL. The point plot gives a diagrammatic explanation of the various parameters we encounter in the ADMET Analysis test. Before docking, energy of both the LIGANDS and the recept or proteins are reduced to the minimum, to make the molecules table and the docking efficient [11-14]. This is the most vital step of this research. All the previous steps were done in order to step up this particular step. The lig and molecules which passed the various steps of ADMET and LIPINSKIRULEOF5 are now required to be docked or bonded with the Receptor (TargetProtein).

\subsection{Lipinski Rule of 5}

Lipinski Rule of 5 is the first parameter that we consider while selecting the drug or natural compounds. The compounds selected in order to target the SSB protein should satisfy the parameters under the LIPINSKI RULE OF 5. The things that are to be seen are:

- H-Bonds Donor should be less than 5

- H-acceptor acceptors should be less than 10

- Log p value should be less than 5

- Molecular weight should be less than 500 Daltons.

\subsection{ADMET Point Plot Result of Sterol}

Here is the point plot diagrammatic result of the drug STEROL. The point plot gives a diagrammatic explanation of the various parameters we encounter in the ADMET analysis test.

Before docking, energy of both the LIGANDS and the receptor proteins are reduced to the minimum, to make the molecules stable and the docking efficient.

Docking is done in order to analyze the ligands in a more appropriate manner. There are more than one ligand testing its binding properties on body is not possible. However, with so many software and tools all over the world, doing in on Insilco is easy. By binding every ligand with the recept or target protein, it can be analyzed how well it is going to bind, and what are the efficiency of the drug.

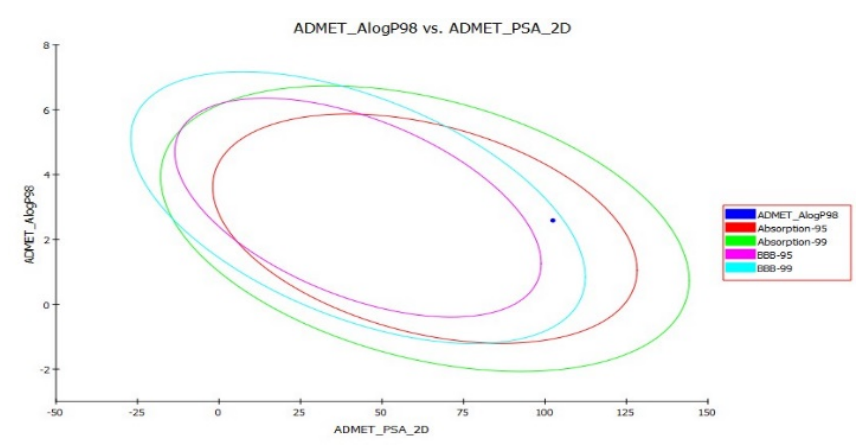

Also docking helps in giving information about the interaction of the drug with the target protein.

\section{RESULT AND DISCUSSION}

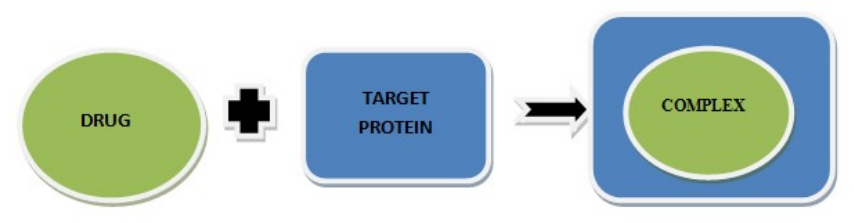

The following are the tools incorporated to compute the values of docking in this work.

1. DiscoveryStudio2.1

2. GOLD

3. HEX5.1 and6.2

\section{DOCKING IN DISCOVERY STUDIO}

The following values are obtained from DISCOVERY STUDIO Docking:

Docking energy:-34.7739; Docking Interaction Energy: 32.694

Docking interaction energy is the parameter on the basis of which, the final drug is choosen. In this case, it is Sterol with maximum docking interaction energy which is 32.694 . Docking is also done in Hex. It is also an automated docking tool which helps in docking the ligands with receptors giving out a range of energy. 


\subsection{Docking in Hex}

Docked structures PDBID2VOO:Pyridoxinein a total of $32 \mathrm{~min}$, 43sec. Starting guess not found in top55961 solutions. Energy range:

Emin=-168.45, Emax=-83.73
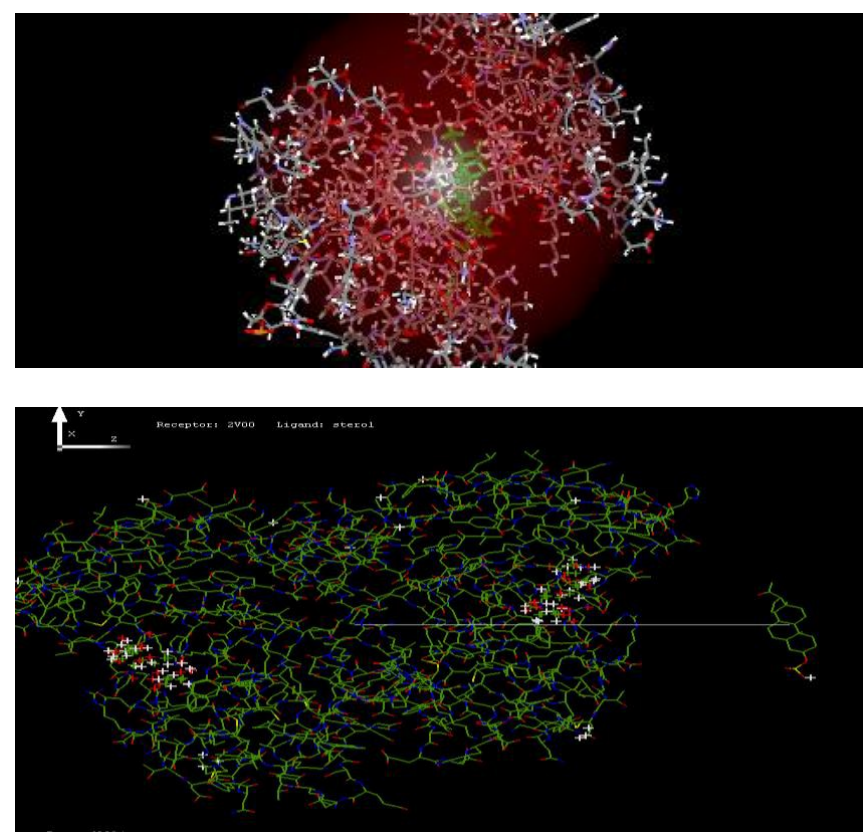

The docking on DISCOVERY STUDIO and HEX provides with their docking energy. Taking into consideration, the interaction energy of Docking, we decide that STEROL is the best drug ligands for targeting SSB protein.

\subsection{Pharmacophore Analysis}

The docked complex of Ligand (STEROL) and Receptor (SSB) is viewed in LIGAND SCOUT.

From the PHARMACOPHORE analysis of the complex STEROL-SSB protein, it is found that the ligand binds with three amino acid of the recept or molecule. The ligand binds with Histidine at $19^{\text {th }}$ position (HIS19A) and with Alanine at $15^{\text {th }}$ and $11^{\text {th }}$ position (ALA15A and ALA11A). It also has 3 hydrophobicbonds, 6 exclusion volumes, 1 negative lyionizableregion. Final Inference states that STEROL binds very well with the SSB protein making it an important compound for the drug for SSB protein in Systemic Lupus Erythematosus. The Paper till now showed that the involvement of the SSB protein is too high in the Disease SLE. SLE is one such kind of disease which has very few alternative store solve the consequences. That is why the following research work was carried on in order to bring out some useful and fruitful drug that can help in the sorting out the problems in SLE.

Through this research, it is found out that there are many organisms that to opossess SSB gene in them. Though not exactly similar like the SSB of HomoSapiens, but a lot of sequences match in a huge percent age with the SSB of
Humans. Thus, by the phylogenetic analysis, we can find out, which model organism is the best for the clinical trials of our drug on the basis of SSB protein.

From phylogenetic analysis it is found that the closest animal on the basis of the SSB protein is Bostaurus. Thus, the clinical and the wet Lab researches can be carried on Bostaurus to check its efficiency in practical. Through Structural analysis, the 3D structure of the protein is obtained. This 3D structure can be viewed on various tools and various new cavities can be retrieved which the automatic tools are not able to find. Also the structural analysis gives option of knowing the various regions available in the protein.

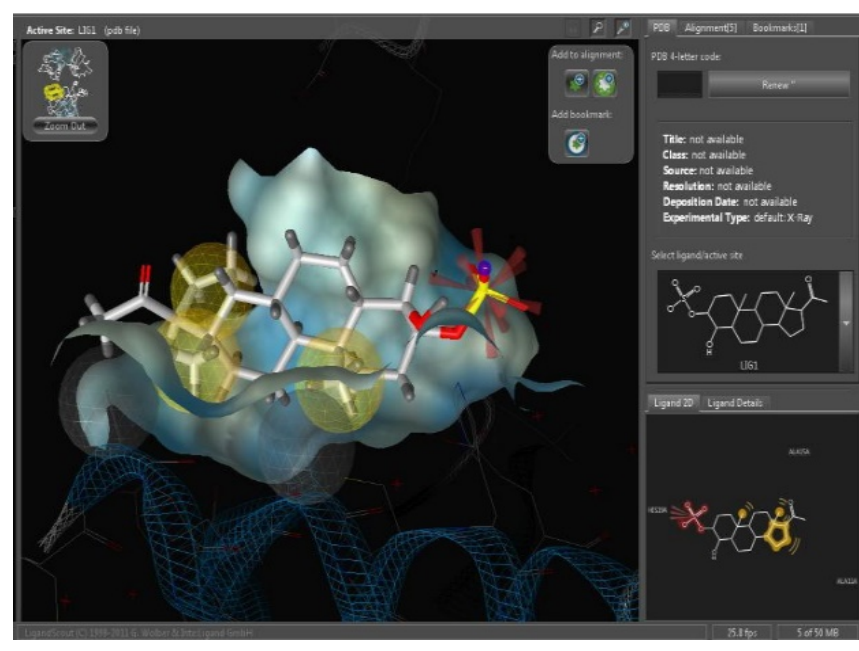

The result that STEROL is the best ligand to deal with the SSB protein. Thus, the further research can use the compound and develop suitable drugs after completing further processes involved. The Pharmacophore analysis also denotes that STEROL binding with the SSB protein is efficient and good. The analysis shows that the bonding of the Ligand molecule is quite efficient.

\section{CONCLUSION}

After all the analysis of the sequence of the protein, several model organisms with the same sequences were obtained. BosTaurus is the closest model organism on the basis of SSB protein.

Other relevance information that we get in our research areas follows:

1. Best target ligand with highest C-Docker interaction energy is Sterol.

2. The pharmacophore analysis also proves that the binding of SSB protein with Sterol is good.

3. Binding happens with histidine at $19^{\text {th }}$ position, alanine at $15^{\text {th }}$ and $11^{\text {th }}$ position.

4. For clinical trial the closest model organism on the basis of SSB protein is bostaurus.

The Pharmacophore analysis also denotes that STEROL binding with the SSB protein is efficient and good. The analysis shows that the bonding of the Ligand molecule is quite efficient. Sterol was best drug receptor. 


\section{REFERENCES}

[1]. Chan, E.K.L.; Sullivan, K.F.; Tan, E.M. "Ribo nucleo protein SSB / La belongs to a protein family with consensus sequences for RNA-binding. "Nucleic Acids Res., 1989, 17, 2233-2244.

[2]. Chambers, J.C.; Kenan, D.; Martin, B.J.; Keene, J.D.J. "Genomic structure and amino acid sequence domains of the human La auto ant igen."Biol.Chem.,1988,263,18043-18051. [3]. Kalnine, N.; Chen,X.; Rolfs, A.; Halleck, A.; Hines, L.; Eisenstein, S.; Koundinya, M.; Raphael, J.; Moreira, D.; Kelley.; LaBaer,J.; Lin,Y.; Phelan,M.; Farmer, A."Cloning of human full-length CDSs in BD Creator (TM) system donor vector."-2003.

[4]. Goshima, N.; Kawamura, Y.; Fukumoto, A.;Miura, A.; Honma, R.; Satoh, R.; Wakamatsu, A .; Yamamoto, J.;Kimura,K.; Nishikawa,T.; And oh,T.;Iida,Y.; Ishikawa,K..; Ito, E.;Kagawa, N.;Kaminaga, C.;Kanehori, K.;Kawakami, B.NomuraN." Human protein factory for converting the transcriptome into aninvitro-expressed proteome."Nat.Methods.2008,5,1011-1017.

[5]. Hillier,L.W.; Graves,T.A.; Fulton,R.S.; Fulton,L.A.; Pepin, K.H.; Minx,P.; Wagner-McPherson, C.; Layman,D.; Wylie,K.; Sekhon,M.; $\quad$ Becker,M.C.; Fewell,G.A.;Delehaunty,K.D.; Miner,T.L.; Nash,W.E.; Kremitzki,C.; Oddy, L.;Du, H.;Wilson, R.K. "Generation and annotation of the DNA sequences of human chromo somes 2 and 4. " Nature.2005,434,724-731.

[6]. Mural,R.J.; Istrail,S.; Sutton,G.G.; Florea,L.; Halpern,A.L.; Mobarry,C.M.; Lippert,R.; Walenz,B.; Shatkay,H.; Dew,I.; Miller,J.R.; Flanigan,M.J.; Edwards,N.J.; Bolanos,R.; Fasulo'D.; Halldorsson,B.V.; Hannenhalli,S.; Turner, R.Cited for: NUCLEOTIDESEQUENCE [LARGE SCALE GENOMICDNA].VenterJ.C.,2005.

[7]. Olsen,J.V.; Blagoev,B.; Gnad,F.; Macek,B.; Kumar,C.; Mortensen,P.; Mann,M. "Global, in vivo and site-specific phosphorylation dynamics in signaling networks. "Cell.2006, 127, 635-648.

[8]. Sturgess,A.D.; $\quad$ Peterson,M.G.; McNeilage,L.J.; Whittingham,S.; Coppel,R.S. "Characteristics and epitope mapping of acloned human autoantigenLa."J.Immunol.1988,140,3212-3218.

[9]. Chambers,J.C.; Keene,J.D. "Isolation and analysis of cDNAclones expressing humanlupusLaantigen. "Proc.Natl.Acad.Sci. U.S.A.1985, 82, 2115-2119.

[10]. Gottlieb,E.; Steitz,J.A. "Function of the mammalianLaprotein: evidence for its action in transcription termination by RNA polymeraseIII."EMBOJ.,1989,8,851861 .

[11]. Fan,H.;Sakulich, A.L.; Goodier,J.L.; Zhang,X..; Qin,J.;Maraie."PhosphorylationofthehumanLaantigenonserin e366canregulaterecyclingofRNApolymeraseIIItranscriptionc omplexes."R.JCell.1997,8,707-715.

[12]. Fouraux,M.A.; Kolkman,M.J.M.; VanderHeijden,A.; DeJong,A.S.; VanVenrooij,W.J.;Pruijn,G " The human
La(SS-B) auto antigen interacts with DDX15/hPrp43, a putative DEAH-box RNAhelicase.",.J.M.RNA..2002,8,14281443.

[13]. Kim,J.-E.;Tannenbaum,S.R.; White,F.M ."Rabip4' is an effector of rab5 and rab4 and regulates transport through early endosomes." "Globalphosphoproteome of HT-29 humancolonadenocarcinomacells."J.ProteomeRes., 2005,4,1 339-1346.

[14]. Theofilopoulos,AN.; Kono, DH.Agenetic analysis oflupus.Allergy.2002,57,(supp172),67-74.

[15]. Bacman,S.; PerezLeiros,C.; Sterin-Borda,L.; Hubsche,rO; Arana,R.; Borda,E. "Auto antibodiesagainstlacrimalglandM3muscarinicacetylcholinere ceptorsinpatientswithprimarySjogren'ssyndrome". InvestOpht halmolVisSci., 1998,39,151-156.

[16]. Bombardieri,M.; Pittoni,V.; Alessandri,C.etal.IL18 in Sjogrensyndrome:"aserologicalandimmunohistochemicalstud y.Sjogren'sSyndrome: Pathogenesis, Clinical Features and Treatment".Program and abstracts of the American College of Rheumatology $67^{\text {th }}$ Annual Scientific Meeting;2003, 2328.

[17]. Anolik,JH.; Barnard,J.; Cappione,A.etal. "Rituximab improves peripheral Bcell abnormalities in human systemiclupuserythematosus".ArthritisRheum., 2004,50,3580 -3590 .

[18]. Atkinson,JC.; Fox,PC. "Sjogren's syndrome: oral and dental considerations".JAmDentAssoc., 1993,124,74-76.7882,84-86.

[19]. Azuma,M.; Aota,K.;Tamatani,T,etal. "Suppression of tumornecros is factor alpha-induced matrix metalloproteinase e9 production in humans alivaryglandacinarcellsbycepharanthine occurs via downregulation of nuclear factor kappaB: a possible the rapeutic agent for preventing the destruction of the acinar structure in the salivary glands of Sjogren's syndrome patients".ArthritisRheum.,2002,46,1585-1594.

[20]. Baecklund,E.; Ekbom,A.; Sparen,P.;etal. "Disease activity and risk of lymphomain patients with rheumatoidarthritis: nested case-control study".BMJ.1998,31,180-181.

[21]. Banner,DW.; D'Arcy,A.; Janes,W,etal. 'Crystal structure of the soluble human 55kdTNF receptor-human TNF beta complex: implications for TNF receptor activation". Cell.1993, 73,431-445.

[22]. Bathon, JM.; Martin,RW.; Fleischmann, RM, etal. “A comparison ofetanercept and methotrexate in patients with early rheumatoidarthritis".NEnglJMed.,2000;343:15861593.

[23]. Bave,U.; Nordmark,G.; Lovgren,T,etal. "Activation of the typeIinterferonsysteminprimarySjogren's syndrome: a possible etiopatho genic mechanism".ArthritisRheum.2005, 52, 1185-1195.

[24]. Hemminki, K.; Li,X.; Sundquist, J.; Sundquist, K. "Familial associations of rheumatoidarthritis with auto immune diseases and related conditions". ArthritisRheum., 
2009,60(3),661-8.

[25]. Mendoza-Pinto, C.; García-Carrasco,M.; SandovalCruz,H,etal. "Risk factors of vertebral fractures in women with systemiclupuserythematosus". Clin. Rheumatol., 2009, 28(5):579-85.

[26]. Syuto, T.; Shimizu, A.; Takeuchi, Y, etal. "Association of antiphosphatidylserine / prothrombin anti bodies with neuropsychiatric systemiclupuserythematosus". Clin. Rheumatol. 2009, 28(7), 841-5.

[27]. Bevra Hannahs Hahn, M.D. "Systemiclupusery the matosus and accelerated atheroscleros is". NEnglJMed., 2003, 349(25),2379-80.

[28]. Mary, J.; Roman, M.D.; Beth-AnnShanker, A.B.; Adrienne Davis, A.B.; Michael, D.; Lockshin, M.D.; Lisa Sammaritano, M.D.; Ronit Simantov, M.D.; Mary, K.; Crow, M.D.; Joseph, E.; Schwartz, Ph.D., Stephen A.Paget, M.D.; Richard B.Devereux, M.D.; and Jane E.Salmon, M.D. "Prevalence and correlates of accelerated atheroscleros is in systemic lupusery the matosus". NEnglJMed., 2003, 349(25), 2399-2406. 